\title{
A prospective study of individual-level social capital and major depression in the United States
}

\section{Citation}

Fujiwara, T, and I Kawachi. 2008. "A Prospective Study of Individual-Level Social Capital and Major Depression in the United States." Journal of Epidemiology \& Community Health 62 (7): 627-33. https://doi.org/10.1136/jech.2007.064261.

\section{Permanent link}

http://nrs.harvard.edu/urn-3:HUL.InstRepos:41288110

\section{Terms of Use}

This article was downloaded from Harvard University's DASH repository, WARNING: This file should NOT have been available for downloading from Harvard University's DASH repository.

\section{Share Your Story}

The Harvard community has made this article openly available.

Please share how this access benefits you. Submit a story.

\section{Accessibility}




\title{
A prospective study of individual-level social capital and major depression in the United States
}

\author{
T Fujimara, ${ }^{1,2}$ | Kawachi ${ }^{3}$
}

\begin{abstract}
${ }^{1}$ Centre for Community Child Health Research, Child and Family Research Institute Vancouver, Canada; ${ }^{2}$ Department of Pediatrics, University of British Columbia, Vancouver, Canada;

${ }^{3}$ Department of Society, Human Development, and Health, Harvard School of Public Health, Boston, USA

Correspondence to: Dr T Fuijwara, Centre for Community Child Health Research, Child and Family Research Institute, 4480 Oak Street, F612B, Vancouver, BC, Canada V6H 3V4; tfujiwara@ cw.bc.ca
\end{abstract}

Accepted 1 October 2007

\begin{abstract}
Study objective: To investigate prospectively the associations between depression and cognitive social capital (social trust, sense of belonging, mutual aid) and structural social capital (volunteer work and community participation).
\end{abstract}

Methods: This was a prospective study that was carried out in the USA. The participants were a nationally representative sample of 724 English-speaking noninstitutionalised adults (25-74 years old) who participated in the National Survey of Midlife Development in the United States (MIDUS) in 1995-6 and the MIDUS Psychological Experience Follow-Up study in 1998.

Main results: In multivariable adjusted logistic regression analyses, those who trusted their neighbours were less likely to develop major depression (MD) during follow-up than those who reported low levels of social capital on these dimensions (adjusted $\mathrm{OR}$ of $\mathrm{MD}$ for high vs low trust $=0.43 ; 95 \% \mathrm{Cl} 0.20$ to 0.93 , adjusted for $\mathrm{MD}$ at baseline, age, gender, race, education, working status, marital status, physical health and extroversion traits).

Structural dimensions of social capital were not associated with MD in adjusted models.

Conclusions: Perceptions of higher levels of cognitive social capital (trust of neighbours) are associated with lower risks of developing MD during 2-3 year follow-up. However, after excluding participants with $\mathrm{MD}$ at the baseline, the association between trust and MD became non-significant. Structural dimensions were not associated with MD.

Social capital has been broadly defined as the resources that individuals access through their networks. ${ }^{1}$ Individuals who lack network ties (ie people who are socially isolated) have been shown to be at increased risk of developing depressive illness. ${ }^{1}$ More recently, interest has also turned toward examining the possible contextual influence of community-based social networks on mental health outcomes. Researchers have begun to ask whether residents of communities with low levels of social integration might also be at increased risk of poor mental health outcomes, net of individual characteristics. ${ }^{1-7}$

In practice, researchers have adopted a variety of indicators to assess social capital, ${ }^{8}$ including trust of others, ${ }^{9}$ sense of belonging to a community, ${ }^{10}{ }^{11}$ mutual assistance between neighbours, ${ }^{12}$ neighbourhood cohesion, ${ }^{13}$ volunteering activity, ${ }^{14}$ group membership ${ }^{15}$ and even voting participation. ${ }^{2}$

Three distinctions have been commonly drawn in the conceptualisation and measurement of social capital. First, indicators have been categorised as tapping either the "cognitive" dimensions of social capital (such as perceptions of trust, as well as beliefs about the extent to which neighbours can be called upon to provide social support) or the "structural" dimensions of social capital, which centre on reports of actual behaviours such as participating in locally based associations. ${ }^{16} \mathrm{~A}$ second distinction in social capital research concerns the level of analysis-whether social capital is treated as an individual-level attribute or as a community-level characteristic. ${ }^{17}$ Thus, some studies have characterised individuals as possessing either higher or lower levels of social capital based upon their network position, or other characteristics of the social networks to which they belong (eg high levels of trust and reciprocity). Other studies have treated social capital as a group-level attribute, and characterised communities as possessing either higher or lower stocks of social capital, based upon aggregated perceptions of cohesion among its members or patterns of social interaction. Yet a third distinction that is increasingly drawn in social capital research involves the differential consequences of "bonding" compared with "bridging" social capital. ${ }^{18}$ "Bonding" capital refers to networks of dense ties between members of a group who are similar to each other with respect to social status, race/ ethnicity and other forms of identification, whereas "bridging" capital refers to bonds that span across such lines of identity.

A growing number of studies have suggested a link between community social capital and mental health. ${ }^{1-47}$ In the UK, a recent study by Fone et al showed that both individual-level and communitylevel cognitive social capital were inversely associated with common mental disorder measured by the Mental Health Inventory, subscale of the SF36. McCulloch ${ }^{3}$ also reported that those who perceive their neighbourhood as low in social capital were more likely to have common mental disorders measured by general health questionnaire (GHO). In Australia, Phongsavan et al ${ }^{4}$ showed that higher cognitive social capital was associated with lower risk of common mental disorder measured by the 10-item Kessler (K10) instrument. Lofors and Sundquist ${ }^{2}$ found that linking social capital (as inferred from mean voting participation within the neighbourhood) was inversely associated with hospitalisation for depression and psychosis in Sweden. A recent longitudinal study in The Netherlands found that one aspect of cognitive social capital, informal social control, was inversely associated with child mental health. ${ }^{19}$ Nonetheless, several questions remain unresolved concerning the association between social capital and mental health. ${ }^{5}$ Previous studies have been limited by their cross-sectional designs, ${ }^{520-24}$ the 
use of non-diagnostic instruments to assess mental health, such as GHO or CES-D, ${ }^{31524-29}$ or the failure to consider both the cognitive and structural domains of social capital. ${ }^{4}$

The National Survey of Midlife Development in the United States (MIDUS) carried out in 1995-6 is a nationally representative sample of middle aged adults (aged 25-74 years old) in the USA that used the Composite International Diagnostic Interview Short Form (CIDI-SF) to assess mental illness, and measured several social capital dimensions, including social trust and community participation. ${ }^{30}$ Although the survey did not provide information about individual residential location (so that a multilevel analysis of community social capital and mental illness could not be carried out), the data nevertheless permitted an analysis linking individual perceptions of community social capital to their mental health outcomes. Furthermore, a randomly selected subset of the MIDUS participants were followed up for 2-3 years after the baseline survey (in 1998) for psychological assessment $(N=724)$, which included the diagnosis of major depression $(\mathrm{MD})$ assessed by the CIDI-SF. ${ }^{31}$ By linking these two waves of the survey, we were able to prospectively examine the association between individual perceptions of community social capital and risk of MD.

Our aim was to test the hypothesis that different dimensions of social capital (social trust, sense of belonging, and mutual aid, volunteer work and community participation) were associated with risk of $\mathrm{MD}$ during the 2-3-year follow-up, after controlling for individual potential confounders.

\section{METHODS}

\section{Source of data: the MIDUS study}

For baseline data, we used the MIDUS data originally collected in 1995-6 as a collaborative, interdisciplinary investigation of the patterns, predictors and consequences of midlife development in the areas of physical health, psychological well-being and social functioning. ${ }^{30}$ Respondents were selected from a nationally representative, random digit dial sample of noninstitutionalised, English-speaking adults aged between 25 and 74 years, who were picked from working telephone banks in the coterminous United States. Detailed information regarding the MIDUS study has been published previously and is available on the MIDMAC website. ${ }^{32}{ }^{33}$ The sample for the current analysis includes original MIDUS respondents who completed the telephone survey (response rate 70\%), which included CIDIbased baseline diagnoses of $\mathrm{MD}$, and the postal questionnaire (response rate $87 \%$ ), which captured information related to community social capital and other covariates. The combined response rate to the telephone survey and the postal questionnaire was $60.8 \%$. Follow-up data were obtained using the Psychological Experiences Follow-Up Study implemented in 1998. ${ }^{31}$ The primary objective of the follow-up study was to explore how adults perceive psychological change in their lives. This study was a random telephone follow-up of 724 respondents of the original MIDUS random digit dial sample ( $82 \%$ response rate among 883 participants selected from the original MIDUS survey who were recontacted). After the study was explained to the informant, a household listing was generated of people in the age range 25-74, and a random respondent was selected. Men and older people were oversampled.

\section{Measures}

MIDUS researchers assessed MD in the original and the followup study using CIDI-SF. ${ }^{34-36}$ The diagnosis of MD was based on the 19 items in the definitions and criteria specified in the DSMIII-R. ${ }^{37}$ A diagnosis of $\mathrm{MD}$ requires a period of at least 2 weeks of either depressed mood or anhedonia most of the day, nearly every day, and a series of at least four other associated symptoms typically found to accompany depression, including problems with eating, sleeping, energy, concentration, feelings of low self-worth, and suicidal thoughts or actions. $\mathrm{MD}$ was assessed by telephone interview in the original and the follow up surveys. In the original MIDUS survey, the time frame for enquiring about symptoms of $\mathrm{MD}$ was the previous 12 months, whereas, in the follow-up MIDUS survey, MD items enquired about the past 5 years to capture all depressive episodes during follow-up. The test-retest reliability and clinical validity of CIDI-SF diagnoses have previously been examined and found to be high. ${ }^{38}$ Psychometric properties are also acceptable: sensitivity was 0.73 and specificity was 0.82 in comparison with semistructured clinical diagnostic interview. ${ }^{39}$ Moreover, the $\mathrm{MD}$ scales employed in the present study were used in a previous publication, in which they were based upon the responses of the MIDUS dataset..$^{40}$

Individual perceptions of community social capital were assessed within cognitive and structural domains. Cognitive social capital indicators included social trust, sense of belonging and mutual aid. Social trust was assessed with a single item"people in my neighbourhood trust each other"-with Likertscale responses ranging from "not at all" to "a little", "some" and "a lot". This single-item measurement of social trust was used in previous study. ${ }^{9}$ The responses "not at all" and "a little" were collapsed a priori in order to create three categories: high trust (38.0 weighted per cent), middle trust (39.6 weighted per cent) and low trust (22.4 weighted per cent).

Sense of belonging was a three-item scale derived as the weighted average of responses to the following items: (1) "I don't feel I belong to anything I'd call a community", (2) "I feel close to other people in my community" and (3) "my community is a source of comfort". Responses to each question were recorded on a seven-point Likert scale, with higher scores denoting a higher sense of belonging. As the resulting sense of belonging index was relatively normally distributed, we analysed it as tertiles (high, medium and low). The internal consistency reliability of the sense of belonging index was acceptable (Cronbach's alpha $=0.73$ ). Mutual aid was a threeitem index calculated as the weighted mean of the following three items: (1) "people who do a favour expect nothing in return", (2) "people do not care about other people's problems" and (3) "I believe that people are kind". Responses were scaled from 1 to 7 , with higher scores denoting higher perceptions of mutual aid. The internal consistency reliability of the mutual aid scale was not as high (Cronbach's alpha $=0.42$ ). The mutual aid scale was also categorised into tertiles.

Structural social capital was assessed by enquiring about volunteer work and community participation. Volunteer work was calculated as the sum of reported hours per month in volunteer work at a hospital, nursing home or other healthrelated settings, at school or other youth-related activities, for political organisations or causes, and/or for any other local organisations or charity. Based on the distribution of responses, we categorised volunteer work into three groups: no volunteer work, 1-9 hours per month, and 10 or more hours per month. Finally, community participation was calculated as the sum of reported frequency of participation per month in religious services, meetings of religious groups, meetings of unions or other professional groups, meetings of sports or social groups, or meetings of any other groups (not including those required by 
the respondent's job). Based on the distribution of responses, we categorised community participation into four groups: no participation, 1-3 times per month, 4-7 times per month, and 8 or more times per month.

All regression analyses controlled for age, gender, race, education, working status, marital status, perceived physical health (assessed with a single question: "in general, would you say your physical health is ...?", with Likert-scale responses ranging from poor to fair, good, very good or excellent), extroversion trait and MD in 1995-6. Extroversion has been associated with the development of depression ${ }^{42}$ and social capital $^{43}$ according to previous studies; therefore, this trait was considered as a confounder which needs to be adjusted. Extroversion was assessed by calculating the mean score of a self-administered questionnaire consisting of five items (outgoing, friendly, lively, active, talkative) with Likert-scale responses ranging from a lot to some, a little and not at all. Cronbach's alpha of this scale was 0.78 . This scale was used in previous studies. ${ }^{44}{ }^{45}$ Detailed categories of each variable are presented in table 1.

\section{Analyses}

Sampling weights were applied to adjust for possible selection bias and differential non-response. ${ }^{31}$ Intercorrelations between social capital variables were analysed by Spearman rank correlation. We performed sequential logistic regressions to examine the relationships of social capital and MD diagnosis. In model 1, we regressed diagnosis of MD in 1998 on social capital indicators in 1995-6, adjusting for baseline diagnosis of MD in 1995. In model 2 , we additionally controlled for age and gender. In model 3, we additionally adjusted for race, education, working status and marital status. Finally, in model 4, we additionally adjusted for baseline perceived physical health and extroversion trait. The number of individuals dropped from analyses owing to missing data was small. With regard to social capital indicators, the number of missing cases was: social trust, 8; sense of belonging, 4; mutual aid, 4; volunteer activity, 9; and community participation, 3 . With regard to subjects who were dropped because of missing covariate information, these were: race, 11; education, 1; working status, 8; and extroversion, 2. After we applied sampling weights in the analyses to approximate a national sample, the final weighted $N$ ranged from 610 to 616, depending on the social capital indicator used. All analyses were carried out with STATA SE statistical package, version 9 (Stata, College Station, TX, USA).

\section{RESULTS}

Table 1 shows demographic and health characteristics of the study sample. Regarding demographic characteristics, $56 \%$ of the sample were women (weighted), $87 \%$ were white, $40 \%$ were high school graduates, $63 \%$ were full-time workers, and $75 \%$ were married. More than $80 \%$ of respondents perceived their physical health as good or better. Twelve per cent of the baseline sample in 1995-6 met the criteria for a diagnosis of $\mathrm{MD}$, whereas the corresponding prevalence was $15 \%$ at followup in 1998.

Being female, of younger age, unemployed (compared with working full time), never married (compared with being married), reporting poor physical health and having a diagnosis of $\mathrm{MD}$ in 1995-6 were each associated with higher risks of $\mathrm{MD}$ diagnosis at follow-up in 1998. Race and education were not associated with MD in 1998. Extroversion trait was associated with MD in 1995-6, but was not associated with MD in 1998.
With regard to the relationships of demographic and health characteristics to social capital indicators, gender was not associated with social capital variables except for community participation-women were more likely than men to report participating in community activities. Older individuals reported higher levels of social capital across all domains with the exception of engaging in volunteer work. Race was related to lower levels of cognitive social capital (ie, lower perceptions of trust, belonging and mutual aid), but not to structural aspects of social capital. Educational attainment was strongly related to structural dimensions of social capital, but not to cognitive dimensions. Retired individuals had higher levels of social capital, whereas the unemployed showed lower levels of social capital. Marital status was associated with high social trust and sense of belonging. Better physical health was associated with higher structural social capital, though not with cognitive social capital (probably reflecting reverse causation). Extroversion trait was positively associated with all social capital indicators.

Table 2 shows the intercorrelations between social capital variables. All social capital variables were significantly correlated with each other. Correlations among cognitive social capital variables ranged from 0.20 to 0.34 , while the two structural social capital scales (volunteering and community participation) were correlated (0.41).

Table 3 shows the weighted unadjusted and adjusted odds ratios of $\mathrm{MD}$ in 1998, according to levels of social capital assessed at baseline. Across models 1-3, MD was statistically significantly associated with social trust and sense of belonging. Even after controlling for baseline $\mathrm{MD}$, socioeconomic status (education, working status) and other covariates (gender, age, race, marital status), high levels of social trust were associated with an odds ratio for $\mathrm{MD}$ of 0.44 (95\% CI 0.20 to 0.95 , weighted $N=613$ ) compared with low levels of trust. The corresponding odds ratio for high versus low sense of belonging was 0.49 (95\% CI 0.24 to 0.99 , weighted $N=617)$, with a p for trend of 0.045 (table 3 , model 3 ). In model 4 (additionally adjusting for baseline physical health status and extroversion trait) the association between trust and $\mathrm{MD}$ remained marginally significant $(\mathrm{OR}=0.43,95 \%$ CI 0.20 to 0.93 , weighted $N=612$ ). The $\mathrm{p}$ value for trend across categories of trust was 0.036, suggesting a "dose-response" effect. However, the association between sense of belonging and $\mathrm{MD}$ became statistically non-significant. No associations were found between mutual aid and $\mathrm{MD}$, nor between the structural dimensions of social capital and $\mathrm{MD}$.

As a further robustness check, we repeated the analyses after excluding those who reported $\mathrm{MD}$ at baseline. In the fully adjusted model, the point estimates of the odds ratio for high social trust in comparison with low social trust was 0.46, although the $95 \%$ CI included 1.0 (95\% CI 0.18 to 1.15 , weighted $N=544$ ). Similarly, sense of belonging was marginally significantly associated with $\mathrm{MD}$ : the point estimate of the odds ratio for the high sense of belonging group in comparison with the low sense of belonging group was 0.45 (95\% CI 0.19 to 1.02 ; weighted $N=546$ ). p for trend for sense of belonging was 0.057 , suggesting a marginally significant dose-response relation. Other social capital variables were not associated with MD. To investigate the interaction between $\mathrm{MD}$ at baseline and social trust and sense of belonging, the analysis was repeated among those who reported $\mathrm{MD}$ at baseline. We found that the odds ratio for high social trust was 0.36 (95\% CI 0.08 to 1.69 , weighted $N=68$ ), suggesting a protective effect of social trust even among those who have $\mathrm{MD}$ at baseline. By contrast, with 
Table 1 Characteristics of sample $(N=724)$

\begin{tabular}{|c|c|c|c|}
\hline Variables & $N$ & Weighted\% & $\%$ SE \\
\hline \multicolumn{4}{|l|}{ Gender } \\
\hline Male & 358 & 44.0 & 2.2 \\
\hline Female & 366 & 56.0 & 2.2 \\
\hline \multicolumn{4}{|l|}{ Age (years) } \\
\hline 25-34 & 105 & 19.5 & 1.9 \\
\hline $35-44$ & 176 & 28.4 & 2.1 \\
\hline $45-54$ & 178 & 18.3 & 1.6 \\
\hline $55-64$ & 170 & 19.4 & 1.8 \\
\hline $65-74$ & 95 & 14.4 & 1.8 \\
\hline \multicolumn{4}{|l|}{ Race $^{*}$} \\
\hline White & 645 & 87.1 & 1.7 \\
\hline Black & 34 & 8.4 & 1.5 \\
\hline Other & 34 & 4.4 & 0.9 \\
\hline \multicolumn{4}{|l|}{ Education* } \\
\hline$<$ High school & 53 & 9.5 & 1.4 \\
\hline High school† & 219 & 40.2 & 2.3 \\
\hline Some college & 224 & 26.3 & 1.8 \\
\hline Graduated college§ & 227 & 24.0 & 1.7 \\
\hline \multicolumn{4}{|l|}{ Working status* } \\
\hline Full-time working & 457 & 62.7 & 2.2 \\
\hline Retired & 118 & 15.1 & 1.6 \\
\hline Homemaker & 80 & 13.4 & 1.7 \\
\hline Unemployment & 61 & 8.8 & 1.3 \\
\hline \multicolumn{4}{|l|}{ Marital status } \\
\hline Married & 512 & 75.2 & 1.9 \\
\hline Separated & 12 & 1.6 & 0.5 \\
\hline Divorced & 89 & 9.1 & 1.2 \\
\hline Widowed & 55 & 6.0 & 1.0 \\
\hline Never married & 56 & 8.2 & 1.3 \\
\hline \multicolumn{4}{|c|}{ Perceived physical health } \\
\hline Poor & 25 & 3.0 & 0.7 \\
\hline Fair & 93 & 14.0 & 1.6 \\
\hline Good & 254 & 34.8 & 2.2 \\
\hline Very good & 243 & 32.0 & 2.1 \\
\hline Excellent & 109 & 16.2 & 1.7 \\
\hline \multicolumn{4}{|c|}{ Major depression in 1995-6 } \\
\hline Yes & 85 & 11.6 & 1.4 \\
\hline \multicolumn{4}{|c|}{ Major depression in 1998} \\
\hline Yes & 115 & 15.4 & 1.6 \\
\hline
\end{tabular}

${ }^{*}$ Total of $N$ is less than grand total $(N=724)$ owing to missing value. $\dagger$ General Educational Development is included.

No bachelor degree is included.

§Professional education is included.

regard to sense of belonging, the odds ratio of high sense of belonging was 0.71 (95\% CI 0.17 to 3.03 , weighted $N=69)$. The interaction term was not statistically significantly between $\mathrm{MD}$ and either social trust or sense of belonging.

\section{DISCUSSION}

The present study suggests that perceptions of higher levels of cognitive social capital (trust of neighbours and sense of belonging) are associated with lower risks of developing $\mathrm{MD}$ during 2-3-year follow-up, even after controlling for socioeconomic status, baseline diagnosis of $\mathrm{MD}$ and other sociodemographic covariates. The association between trust and $\mathrm{MD}$ remains statistically significant even after controlling for baseline physical health status and extroversion trait (table 3, model 4). However, after excluding participants with $\mathrm{MD}$ at baseline, the association between trust and $\mathrm{MD}$ became non-significant. Structural dimensions of social capital were not associated with $\mathrm{MD}$.

Our results are consistent with some previous studies which found individual cognitive social capital to be inversely
Table 2 Intercorrelations between social capital variables

\begin{tabular}{llllll}
\hline Social capital components & $\mathbf{1}$ & $\mathbf{2}$ & $\mathbf{3}$ & $\mathbf{4}$ & $\mathbf{5}$ \\
\hline 1. Social trust & - & & & & \\
2. Sense of belonging & $0.34^{* *}$ & - & & & \\
3. Mutual aid & $0.20^{* *}$ & $0.27^{* *}$ & - & & \\
4. Volunteer work & $0.11^{* *}$ & $0.25^{* *}$ & $0.08^{* *}$ & - & \\
5. Community participation & $0.12^{* *}$ & $0.28^{* *}$ & $0.11^{* *}$ & $0.41^{* *}$ & - \\
\hline
\end{tabular}

Social trust, sense of belonging and mutual aid were categorised into low, middle and high; volunteer work was categorised into no volunteer work, 1-9 hours/month and $\geqslant 10$ hours/month; and community participation was categorised into no participation, 1-3 times/month, 4-7 times/month and $\geqslant 8$ times/month.

${ }^{* *} \mathrm{p}<0.01$.

associated with common mental disorder. ${ }^{72426-28}$ For example, Fone et $\mathrm{al}^{7}$ reported inverse associations between individual-level and community-level cognitive social capital and common mental disorder using the same data. In another study, ecological social capital (measured as social cohesion) was inversely associated with psychotic morbidity within electoral wards in the UK. ${ }^{46}$ Linking social capital was inversely associated with the risk of hospitalisation due to depression, net of individual covariates, in Sweden. ${ }^{2}$ On the other hand, Rosenheck et $a l^{47}$ reported that social capital, measured by both cognitive and structural dimensions, was not associated with depression or psychosis (assessed by C-DIS-R and PERI) among homeless people with severe mental illness in the USA using a longitudinal design.

Although our sample size is not very large, we used a nationally representative sample of middle-aged adults in the USA. To our knowledge, this is the first study to show the association between social capital and $\mathrm{MD}$ within a nationally representative sample, using diagnoses based on the DSM, and based on a prospective longitudinal design. The longitudinal design of our study reduces the likelihood of reverse causation (ie, the possibility that mental illness either led to lower perceptions of trust and belonging or that individuals with better mental health moved to more cohesive communities), which has limited the interpretation of cross-sectional studies. We hasten to add that, even with a longitudinal study design, we cannot rule out the possibility of common method bias. In other words, individuals with negative affect at baseline (who would have been at increased risk of developing $\mathrm{MD}$ during the course of follow-up) were more likely to negatively evaluate trust and other aspects of social capital within their communities. The ideal design to overcome this bias would have been to assess community social capital from an independent source (eg, a community survey in a separate sample), or to aggregate the responses of residents living within the same community. ${ }^{48}$ Unfortunately, the MIDUS data did not permit us to aggregate (and average) the perceptions of individuals living within the same community, which is clearly the limitation of this study. Our inability to measure social capital at the ecological level precluded differentiating whether the "places" people live matters for $\mathrm{MD}$, or whether the perception of individuals toward "place" matters for MD.

To address common method bias, we adjusted for extroverted personality trait, and found that both trust and sense of belonging continued to be associated with lower risks of $\mathrm{MD}$. However, when we excluded $\mathrm{MD}$ at baseline, the associations became non-significant, although the point estimates of the odds ratios were quite similar $(0.43$ and 0.46 for trust and sense of belonging respectively). The exclusion of those who had MD at baseline (68 weighted cases) possibly reduced our power to detect a statistically significant association between social trust 
Table 3 Weighted percentage of major depression by social capital level and weighted unadjusted and adjusted odds ratios of logistic regression of social capital variables on major depression in 1998

\begin{tabular}{|c|c|c|c|c|c|c|}
\hline \multirow[b]{2}{*}{ Social capital variables } & \multirow[b]{2}{*}{$\begin{array}{l}\text { Weighted } \\
\text { percentage }\end{array}$} & \multirow[b]{2}{*}{$\begin{array}{l}\text { Unadjusted OR } \\
(95 \% \mathrm{CI})\end{array}$} & \multicolumn{4}{|c|}{ Adjusted OR (95\% CI) } \\
\hline & & & $\begin{array}{l}\text { Model } 1 \\
\text { (+ depression in } \\
1995-6)\end{array}$ & $\begin{array}{l}\text { Model } 2 \\
\text { (+ age, gender) }\end{array}$ & $\begin{array}{l}\text { Model } 3 \text { (+race, } \\
\text { education, } \\
\text { working status, } \\
\text { marital status) }\end{array}$ & $\begin{array}{l}\text { Model } 4 \text { (+ } \\
\text { perceived physical } \\
\text { health, extroversion } \\
\text { trait) }\end{array}$ \\
\hline \multicolumn{7}{|l|}{ Cognitive social capital } \\
\hline \multicolumn{7}{|l|}{ Social trust } \\
\hline Weighted $N$ & & 628 & 628 & 628 & 613 & 612 \\
\hline Low & 22.4 & 1.00 & 1.00 & 1.00 & 1.00 & 1.00 \\
\hline Middle & 39.6 & $0.51(0.28-0.93)$ & $0.59(0.32-1.11)$ & $0.59(0.31-1.13)$ & $0.60(0.30-1.18)$ & $0.58(0.29-1.14)$ \\
\hline High & 38.0 & $0.34(0.18-0.64)$ & $0.39(0.20-0.75)$ & $0.42(0.20-0.85)$ & $0.44(0.20-0.95)$ & $0.43(0.20-0.93)$ \\
\hline$p$ for trend & & 0.001 & 0.006 & 0.017 & 0.039 & 0.036 \\
\hline \multicolumn{7}{|l|}{ Sense of belonging } \\
\hline Weighted $N$ & & 632 & 632 & 632 & 617 & 615 \\
\hline Low & 31.7 & 1.00 & 1.00 & 1.00 & 1.00 & 1.00 \\
\hline Medium & 32.6 & $0.67(0.38-1.20)$ & $0.69(0.38-1.27)$ & $0.70(0.38-1.29)$ & $0.73(0.39-1.38)$ & $0.70(0.37-1.33)$ \\
\hline High & 35.7 & $0.42(0.23-0.77)$ & $0.42(0.22-0.80)$ & $0.46(0.24-0.90)$ & $0.49(0.24-0.99)$ & $0.51(0.25-1.04)$ \\
\hline $\mathrm{p}$ for trend & & 0.004 & 0.008 & 0.022 & 0.045 & 0.062 \\
\hline \multicolumn{7}{|l|}{ Mutual aid } \\
\hline Weighted $N$ & & 632 & 632 & 632 & 617 & 615 \\
\hline Low & 33.8 & 1.00 & 1.00 & 1.00 & 1.00 & 1.00 \\
\hline Medium & 30.8 & $0.69(0.38-1.27)$ & $0.73(0.40-1.34)$ & $0.75(0.41-1.39)$ & $0.83(0.43-1.58)$ & $0.84(0.41-1.70)$ \\
\hline High & 35.4 & $0.83(0.47-1.47)$ & $0.93(0.50-1.71)$ & $0.99(0.52-1.88)$ & $1.08(0.54-2.16)$ & $1.09(0.52-2.25)$ \\
\hline $\mathrm{p}$ for trend & & 0.524 & 0.815 & 0.968 & 0.831 & 0.817 \\
\hline \multicolumn{7}{|l|}{ Structural social capital } \\
\hline \multicolumn{7}{|l|}{ Volunteer work } \\
\hline Weighted $N$ & & 628 & 628 & 628 & 612 & 610 \\
\hline No volunteer work & 61.6 & 1.00 & 1.00 & 1.00 & 1.00 & 1.00 \\
\hline 1-9 hours/month & 19.7 & $0.65(0.33-1.26)$ & $0.74(0.37-1.47)$ & $0.76(0.38-1.51)$ & $0.77(0.37-1.61)$ & $0.81(0.38-1.72)$ \\
\hline$\geqslant 10$ hours/month & 18.7 & $1.35(0.73-2.48)$ & $1.62(0.86-3.05)$ & $1.61(0.86-3.00)$ & $1.57(0.79-3.11)$ & $1.64(0.83-3.24)$ \\
\hline$p$ for trend & & 0.587 & 0.263 & 0.256 & 0.325 & 0.251 \\
\hline \multicolumn{7}{|l|}{ Community participation } \\
\hline Weighted $N$ & & 634 & 634 & 634 & 618 & 616 \\
\hline No participation & 26.6 & 1.00 & 1.00 & 1.00 & 1.00 & 1.00 \\
\hline $1-3$ times/month & 18.6 & $1.00(0.50-1.98)$ & $1.09(0.52-2.31)$ & $1.02(0.47-2.21)$ & $0.97(0.45-2.13)$ & $1.05(0.47-2.35)$ \\
\hline 4-7 times/month & 24.3 & $0.78(0.39-1.54)$ & $0.95(0.46-1.96)$ & $1.00(0.48-2.09)$ & $0.94(0.45-1.98)$ & $1.02(0.48-2.16)$ \\
\hline$\geqslant 8$ times/month & 30.5 & $0.69(0.35-1.34)$ & $0.83(0.41-1.67)$ & $0.81(0.39-1.66)$ & $0.70(0.34-1.47)$ & $0.77(0.35-1.71)$ \\
\hline $\mathrm{p}$ for trend & & 0.209 & 0.544 & 0.564 & 0.357 & 0.530 \\
\hline
\end{tabular}

and $\mathrm{MD}$, resulting in an imprecise risk estimate. An alternative interpretation is that social trust helps depressed people to recover from their illness, but does not affect the incidence of $\mathrm{MD}$. Our findings do not allow us to conclude that social trust "prevents" the onset of MD. Rather, living in a high social trust community may be beneficial for depressed people as residents in such places might have better access to affective support, which may improve their prognosis. ${ }^{79}$ Additional, longer follow-up studies are needed to investigate the association between social capital and $\mathrm{MD}$.

The protective effect of social trust for $\mathrm{MD}$ can be interpreted in two ways. First, living in a community with higher social trust may have a direct protective effect for $\mathrm{MD}$ (main effect). ${ }^{1}$ Individual interactions with trusting neighbours may produce positive psychological states, such as a sense of being "accepted" within the community. Alternatively, higher social trust within a community may foster health-related social norms (ie, more physical activity, non-smoking), which may have a protective effect for $\mathrm{MD}$. A recent multilevel study showed that living in a deprived neighbourhood is associated with depressive symptoms. ${ }^{50}$ Further multilevel studies are needed to test the existence of contextual effects of social trust on MD. Second, those who live in a high trust community may find it easier to obtain social support from neighbours to cope with daily stress (stress-buffering model). ${ }^{1}$ An explicit test of the stress-buffering model requires checking for a cross-level interaction term between community social capital and individual experiences of stress.

A notable finding of our study was that, although cognitive dimensions of social capital (trust in particular) were associated with $\mathrm{MD}$, structural dimensions (volunteering and community participation) were not. This emphasises the importance of assessing different dimensions of social capital, since they may not be associated with health outcomes to the same degree. Our finding echoes recent reports indicating that volunteering and community participation are not always associated with better health outcomes (even though endogeneity bias might predict that they would be, ie, healthier people tend to volunteer and to participate in local activities). ${ }^{51}$ In a previous review article, it was reported that none of the studies of structural capital (measured at the ecological level) found an association with common mental disorder or suicide..$^{5}$ In addition, in a study of a working class suburb in Adelaide, Australia, Ziersch and Baum ${ }^{52}$ found that involvement in community groups was associated with worse physical health as measured by the SF-12 health status survey. Qualitative interviews with residents in the same 


\section{What this study adds}

A growing number of studies have suggested a link between community social capital and mental health; however, the association remains inconclusive. We conducted a longitudinal study to examine the association between both cognitive and structural social capital and mental health, using DSM diagnostic criteria. Our findings showed that high cognitive social capital, specifically social trust but not structural social capital, was associated with lower risk of MD. However, after excluding participants with $\mathrm{MD}$ at baseline, the association between trust and MD became non-significant.

\section{Policy implication}

Further empirical studies are warranted before the existing findings on social capital can be translated into effective interventions to promote mental health.

study found that respondents were more likely to view their participation in local community groups as emotionally and physically draining. ${ }^{52}$

In addition, recent research has also begun to emphasise the importance of distinguishing between the effects of so-called bonding and bridging social capital. ${ }^{18}$ Bonding capital refers to resources that are accessed within social groups whose members are alike ("homophilous") in terms of their social identity, such as class or race. By contrast, bridging capital refers to the resources accessed by individuals and groups through connections that cross class, race/ethnicity and other boundaries of social identity. The importance of distinguishing between these two types of capital was illustrated in a small study of a disadvantaged minority community in Birmingham, Alabama, where Mitchell and LaGory ${ }^{15}$ reported that high bonding social capital (measured by the strength of trust and associational ties with others of a similar racial and educational background as the respondent) was paradoxically associated with worse levels of mental distress. In the same study, however, individuals who reported social ties to others who were unlike them with respect to race and class (ie, who had access to bridging capital) were less likely to report mental distress. ${ }^{15}$ Unfortunately, the social capital questions on the MIDUS survey did not permit us to distinguish between bonding and bridging social capital, though doing so may have helped us to understand why variables such as mutual aid did not appear to be associated with risk of MD.

In summary further empirical studies are warranted before the existing findings on social capital can be translated into effective interventions to promote mental health. Meanwhile, the present study has attempted to advance the evidence base in three incremental respects: (1) by utilising a longitudinal design, (2) by adopting a DSM-based diagnosis of MD as the outcome, and (3) by examining the links to both cognitive and structural aspects of community social capital.

Competing interests: None.

\section{REFERENCES}

. Kawachi I, Berkman LF. Social ties and mental health. J Urban Health 2001;78:45867.

2. Lofors J, Sundquist K. Low-linking social capital as a predictor of mental disorders: A cohort study of 4.5 million Swedes. Soc Sci Med 2007;64:21-34.
3. McCulloch A. Social environments and health: cross sectional national survey. BMJ 2001;323:208-9.

4. Phongsavan P, Chey T, Bauman A, et al. Social capital, socio-economic status and psychological distress among Australian adults. Soc Sci Med 2006;63:2546-61.

5. De Silva MJ, McKenzie K, Harpham T, et al. Social capital and mental illness: a systematic review. J Epidemiol Community Health 2005:59:619-27.

6. McKenzie K, Whitley R, Weich S. Social capital and mental health. Br J Psychiatry 2002;181:280-3.

7. Fone DL, Dunstan FD, Lloyd K, et al. Does social cohesion modify the association between area income deprivation and mental health? A multilevel analysis. Int J Epidemiol 2007;36:338-45.

8. Lochner K, Kawachi I, Kennedy BP. Social capital: a guide to its measurement. Health Place 1999:5:259-70.

9. Kawachi I, Kennedy BP, Lochner K, et al. Social capital, income inequality, and mortality. Am J Public Health 1997;87:1491-8.

10. Buckner JC. The development of an instrument to measure neighborhood cohesion. Am J Community Psychol 1988:16:771-91.

11. Harpham T, De Silva MJ, Tuan T. Maternal social capital and child health in Vietnam J Epidemiol Community Health 2006;60:865-71.

12. Skrabski A, Kopp M, Kawachi I. Social capital and collective efficacy in Hungary: cross sectional associations with middle aged female and male mortality rates. J Epidemiol Community Health 2004;58:340-5.

13. Fone DL, Farewell D, Dunstan FD. An ecometric analysis of neighbourhood cohesion Popul Health Metr 2006;4:17.

14. Weitzman ER, Kawachi I. Giving means receiving: the protective effect of social capital on binge drinking on college campuses. Am J Public Health 2000;90:1936-9.

15. Mitchell CU, LaGory M. Social capital and mental distress in an impoverished community. City Community 2002;1:199-222

16. Harpham T, Grant E, Thomas E. Measuring social capital within health surveys: key issues. Health Policy Plan 2002;17:106-11.

17. Kawachi I. Commentary. Social capital and health: making the connections one step at a time. Int J Epidemiol 2006;35:989-93.

18. Szreter S, Woolcock M. Health by association? Social capital, social theory, and the political economy of public health. Int J Epidemiol 2004;33:650-67.

19. Drukker M, Kaplan C, Feron F, et al. Children's health-related quality of life, neighbourhood socio-economic deprivation and social capital. A contextual analysis. Soc Sci Med 2003;57:825-41.

20. Stevenson HC. Raising safe villages: Cultural-ecological factors that influence the emotional adjustment of adolescents. J Black Psychol 1998;24:44-59.

21. Caughy MO, O'Campo PJ, Muntaner C. When being alone might be better: neighborhood poverty, social capital, and child mental health. Soc Sci Med 2003;57:227-37.

22. Rose R. How much does social capital add to individual health? A survey study of Russians. Soc Sci Med 2000;51:1421-35.

23. Harpham T, Grant E, Rodriguez C. Mental health and social capital in Cali, Colombia. Soc Sci Med 2004; 58:2267-77.

24. Steptoe A, Feldman PJ. Neighborhood problems as sources of chronic stress: development of a measure of neighborhood problems, and associations with socioeconomic status and health. Ann Behav Med 2001;23:177-85.

25. Mulvaney C, Kendrick D. Depressive symptoms in mothers of pre-school children: effects of deprivation, social support, stress and neighbourhood social capital. Soc Psychiatry Psychiatr Epidemiol 2005;40:202-8.

26. Ellaway A, Maclntryre S, Kearns A. Perception of place and health in socially contrasting neighbourhoods. Urban Studies 2001;38:2299-316.

27. Boreham R, Stafford M, Taylor R, eds. Health survey for England 2000: social capital and mental health. London: The Stationery Office, 2003.

28. Pevalin D. Rose D. Social capital for health: investigating the links between social capital and health using the British Household panel survey. London: Health Department Agency, 2003.

29. Brown DR, Gary LE, Greene AD, et al. Patterns of social affiliation as predictors of depressive symptoms among urban blacks. J Health Soc Behav 1992;33:242-53.

30. Brim OG, Baltes PB, Bumpass LL, et al. National Survey of Midlife Development in the United States (MIDUS), 1995-1996. 2nd ICPSR version. Ann Arbor, Ml: Interuniversity Consortium for Political and Social Research, 2003.

31. Wethington E, Kessler RC, Brim OG. Midlife Development in the United States (MIDUS): Psychological Experiences Follow-Up Study, 1998. ICPSR02911-v1. Ann Arbor, Ml: Inter-university Consortium for Political and Social Research, 2005.

32. Brim OG. MacArthur Foundation study of successful midlife development. ICPSR Bulletin 2000;20:1-5

33. The John D. and Catherine T. MacArthur Foundation. MIDMAC. http://midmac.med harvard.edu/research.html (accessed 20 April 2006).

34. Kessler RC, Andrews A, Mroczek D, et al. The World Health Organization Composite International Diagnostic Interview Short-Form (CIDI-SF). Int J Methods Psychiatr Res 1998; 7:171-85

35. Wittchen HU. Reliability and validity studies of the WHO Composite International Diagnostic Interview (CIDI): A critical review. J Psychiatr Res 1994;28:57-84.

36. World Health Organization. Composite International Diagnostic Interview, CIDI, Version 1.0. Geneva: World Health Organization, 1990.

37. American Psychiatric Association. Diagnostic and Statistical Manual of Mental Disorders. 3rd edn. Washington, DC: American Psychiatric Association, 1987.

38. Blazer DG, Kessler RC, McGonagle KA, et al. The prevalence and distribution of major depression in a national community sample: the National Comorbidity Survey. Am J Psychiatry 1994;151:979-86. 
39. Aalto-Setala T, Haarasilta L, Marttunen M, et al. Major depressive episode among young adults: CIDI-SF versus SCAN consensus diagnoses. Psychol Med 2002:32:1309-14.

40. Kessler RC, Mickelson KD, Williams DR. The prevalence, distribution, and mental health correlates of perceived discrimination in the United States. J Health Soc Behav 1999;40:208-30.

41. Fujiwara T. The role of altruistic behavior in generalized anxiety disorder and major depression among adults in the United States. J Affect Disord 2007;101:219-25.

42. Kendler KS, Gatz M, Gardner CO, et al. Personality and major depression: a Swedish longitudinal, population-based twin study. Arch Gen Psychiatry 2006;63:1113-20.

43. Lounsbury JW, DeNeui D. Collegiate psychological sense of community in relation to size of college/university and extroversion. J Community Psychol 1996;24:381-94.

44. Keyes CL, Shmotkin D, Ryff CD. Optimizing well-being: the empirical encounter of two traditions. J Pers Soc Psychol 2002;82:1007-22.

45. Staudinger UM, Fleeson W, Baltes PB. Predictors of subjective physical health and global well-being: Similarities and differences between the United States and Germany. J Pers Soc Psychol 1999;76:305-19.
46. Boydell J, McKenzie K, van Os J, et al. The social causes of schizophrenia: an investigation into the influence of social cohesion and social hostility-report of a pilot study. Schizophr Res 2002;53:264.

47. Rosenheck R, Morrissey J, Lam J, et al. Service delivery and community: social capital, service systems integration, and outcomes among homeless persons with severe mental illness. Health Serv Res 2001;36:691-710.

48. Kawachi I, Kim D, Coutts A, et al. Commentary. Reconciling the three accounts of social capital. Int J Epidemiol 2004;33:682-90.

49. Kawachi I, Berkman L. Social cohesion, social capital, and health. In: Kawachi I, Berkman L, eds. Social epidemiology. New York: Oxford University Press, 2000.

50. Kubzansky LD, Subramanian SV, Kawachi I, et al. Neighborhood contextual influences on depressive symptoms in the elderly. Am J Epidemiol 2005;162:253-60.

51. Ellaway A, Macintyre S. Is social participation associated with cardiovascular disease risk factors? Soc Sci Med 2007:64:1384-91.

52. Ziersch AM, Baum FE. Involvement in civil society groups: Is it good for your health? J Epidemiol Community Health 2004;58:493-500.

\section{BMJ Careers online re-launches}

BMJ Careers online has re-launched to give you an even better online experience. You'll still find our online services such as jobs, courses and careers advice, but now they're even easier to navigate and quicker to find.

New features include:

- Job alerts - you tell us how often you want to hear from us with either daily or weekly alerts

- Refined keyword searching making it easier to find exactly what you want

- Contextual display - when you search for articles or courses we'll automatically display job adverts relevant to your search

- Recruiter logos linked directly to their organisation homepage - find out more about the company before you apply

- RSS feeds now even easier to set up

Visit careers.bmj.com to find out more. 